\title{
Towards a digital world
}

\author{
By Danielle Mihram \\ Western European Languages Librarian \\ New York University
}

\section{The Seventh Annual Pacific Telecommunications Conference (PTC '85).}

anuary 1985 marked the first year for the inclusion of a working group of librarians and information specialists in the program of the seventh annual meeting of the Pacific Telecommunications Conference (PTC '85), held in Honolulu, Hawaii, January $13-16,1985)$.

As its very name indicates, issues discussed at that meeting focus on one specific geographical area of the world, the Pacific, and, more specifically, the development and use of telecommunications in the nations which are located in that area. However, though the theme is regional in its orientation, interest in the conference is world-wide: this year's participants came from about thirty countries (including Europe, India, Pakistan and the Eastern United States) and the Pacific Islands.

The conference, whose main theme this year was "Toward a Digital World," included plenary and regular sessions, as well as "Teletrack Sessions" (a series of videotaped presentations running parallel to regular sessions, and replayed, upon request, for participants in their own hotel room), workshops, and exhibits. Each day's papers concentrated on one major theme so that, as papers were presented from one day to the next, participants were able to follow a well-organized development of the conference's titular theme.

The first day's theme, "Development of Digital Channels of Communication," dealt with the concept of a digital world and its various current technological developments, while the second day's theme turned toward considerations of utilization of these channels of communication: technical and engineering aspects, the planning and installation of local area networks, and the decisions involved regarding integrated services and digital networks. The final day's papers, "Managing the Channels and Planning for Transition," centered around discussions of international policy and policy-making for a digital world.

A library workshop, "Pan Pacific Library Interconnection," headed by Carmela Ruby (California State Library, Sacramento), was organized (and attended by about fifteen participants) to identify specific ways to increase and facilitate the flow of information among Pacific rim countries. Indeed, a few of the participants felt that the West Coast of the United States could be considered as being part of the Pacific rim and, as such, is a geographical group whose concerns are not well represented in ALA in view of its national rather than international orientation. It was thus felt that, perhaps, future similar workshops should be a regular feature of the PTC.

Gwen Culp gave an overview of the Washington Library Network Computer Service (WLN) and the Linked Systems Project (LSP), and Bart Kane (Hawaii State Library) commented on the current local, political, and fiscal obstacles in international cooperative activities. He underscored the need for studies of protocols governing trans-border information flow, as well as the need for serious considerations of costs when this technology is being implemented. 
Regrettably, since the presentations of workshops were not included in the conference's proceedings, there is no published access to Culp's and Kane's notes ("The Washington Library Network and the Linked Systems Project," and "Telecommunications for Improved Information Flow to Users," respectively). However, papers presented at the plenary and regular sessions, as well as Teletrack, have been published in the Proceedings, Telecommunications For Pacific Development: PTC '85-Toward a Digital World (Dan J. Wedemeyer, ed., Honolulu, Hawaii: Pacific Telecommunications Council, 1985).

The theme for next year's conference is "Evolution of the Digital Pacific" (PTC '86, Honolulu, January 12 15, 1986), and a library workshop, "Library Networks," will be held on Tuesday afternoon, January 14. For information regarding pre-registration and the call for papers for PTC '87 write to: Pacific Telecommunications Council, 1110 University Avenue, Suite 308, Honolulu, HA 96826.

The relatively high registration fee (preregistration ranging from $\$ 300-400$ ) may be prohibitive to many librarians. The Conference's continuing annual expansion (400 participants in 1985) might therefore be enhanced if the organizers could have a significantly reduced fee for participants from academia and libraries.

Editor's note: The ACRL Professional Association Liaison Committee may be able to assist librarians who give presentations at non-library professional associations. For more information, contact Joan Chambers, Director, Morgan Library, Colorado State University, Fort Collins, CO 80523.

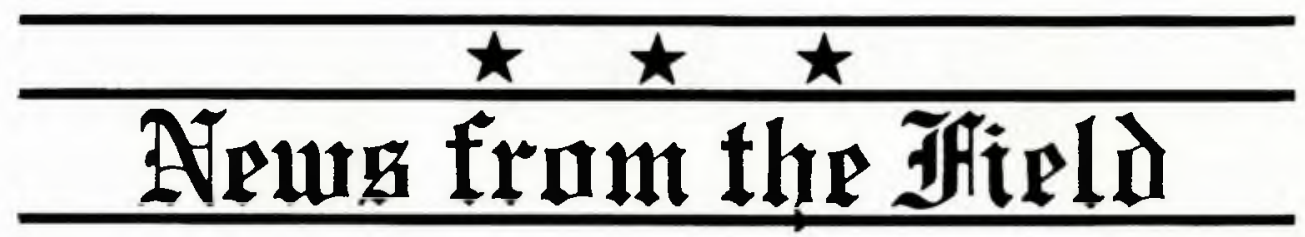

\section{Acquisitions}

- Syracuse University's George Arents Research Library, New York, has acquired the largest known private collection of Steven Crane materials. The collection contains 62 letters by Crane, 39 letters by his wife, a portion of his sister's diary, as well as numerous books, photos, and related materials. Originally owned by the late Crane scholar Melvin H. Schoberlin, the materials were stored by his widow in Oahu, Hawaii, before their transfer to Syracuse. Highlights of the collection include Crane's earliest surviving manuscript, a poem written when he was 10 or 11 years old; four inscribed presentation copies of Crane novels; and letters written for Crane by his wife during the last six months of his life.

- The University of Wisconsin-Platteville has received a unique surname index to persons located in the Upper Mississippi lead and zinc mining district from 1815 through the 1860 s. Gerald Fieldhouse, of Dodgeville, Wisconsin, has spent the last 25 years compiling this index of people who lived, worked, or passed through southwest Wisconsin and northwestern Illinois. The sources used include the Wisconsin territorial census between 1836 and 1847, the Illinois and Michigan census for 1830 and 1840 , the federal census for 1850 and 1860 , and many other local polls and records.

\section{Grants}

- The Boston Library Consortium has been awarded a grant of $\$ 10,000$ from the Florence Roblee Foundation to develop a training module to assist librarians in dealing effectively with the human impact of technological change. The funds will support an initial survey of practicing librarians to identify relevant issues, and the development of a model workshop which will be presented and tested with representatives from a variety of Massachusetts libraries. Materials produced and collected for the project will be edited and made available so that the workshop may be replicated by other libraries and consortia.

- Columbia College's Center for Black Music Research, Chicago, has received a grant of $\$ 30,000$ from the Lloyd A. Fry Foundation for the establishment of a computerized reference system and a union catalogue of black music holdings in selected Chicago-area libraries.

- The Moravian Music Foundation, WinstonSalem, North Carolina, has received two grants totaling $\$ 43,832$ to support the preservation of its archival collections of manuscript music. The John Wesley and Anna Hodgin Hanes Foundation presented $\$ 10,414$ and the James G. Hanes Memorial Fund/Foundation gave an additional $\$ 33,418$. The conservation program was started by a $\$ 25,200$ 